January 2001

\title{
Acute haemolysis in childhood falciparum malaria
}

\author{
H. Ekvall \\ Karolinska Hospital \\ P. Arese \\ University of Torino \\ F. Turrini \\ University of Torino \\ K.Ayi \\ University of Torino
}

F. Mannu

University of Torino

See next page for additional authors

Follow this and additional works at: http://ecommons.aku.edu/eastafrica_fhs_mc_pathol Part of the Pathology Commons

\section{Recommended Citation}

Ekvall, H., Arese, P., Turrini, F., Ayi, K., Mannu, F., Premji, Z., Bjorkman, A. (2001). Acute haemolysis in childhood falciparum malaria. Transactions of the Royal Society of Tropical Medicine and Hygiene, 95(6), 611-617.

Available at: http://ecommons.aku.edu/eastafrica_fhs_mc_pathol/85 
Authors

H. Ekvall, P. Arese, F. Turrini, K. Ayi, F. Mannu, Zul Premji, and A. Bjorkman 


\title{
Acute haemolysis in childhood falciparum malaria
}

\author{
H. Ekvall ${ }^{\star}$, P. Arese ${ }^{2}$, F. Turrini ${ }^{2}$, K. Ayi ${ }^{2}$, F. Mannu ${ }^{2}$, Z. Premij ${ }^{3}$ and A. Bjorkman ${ }^{1}{ }^{1}$ Unit of Infectious \\ Diseases, Karolinska Institutet, Karolinska Hospital, 17176 Stockholm, Sweden; ${ }^{2}$ Department of Genetics, Biology and \\ Biochemistry, University of Torino, 10126 Torino, Italy; ${ }^{3}$ Department of Parasitology and Entomology, Muhimbili University \\ College of Health Sciences, P.O. Box 65011, Dar es Salaam, Tanzania
}

\begin{abstract}
Acute haemolysis associated with clinical episodes of high-level Plasmodium falciparum parasitaemia was studied in 20 children from an holoendemic area (coastal Tanzania). The change in blood haemoglobin $(\mathrm{Hb})$ concentration ranged from -46 to $+5 \mathrm{~g} / \mathrm{L}$ during the $72-\mathrm{h}$ observation period and was linearly related to maximum parasitaemia. Balance studies between loss of blood $\mathrm{Hb}$, increase in plasma $\mathrm{Hb}$ and appearance of $\mathrm{Hb}$ in the urine indicated that extravascular clearance of red cells was the predominant mode of erythrocyte clearance. Most subjects, however, showed minor signs of intravascular haemolysis. The plasma $\mathrm{Hb}$ was $\ll 1 \%$ of blood $\mathrm{Hb}$ and haemoglobinuria was detected in $14 / 20$ children but the excretion of $\mathrm{Hb}$ in urine was $<0.5 \%$ of total $\mathrm{Hb}$ loss. Haemoglobinuria was, however, a marker of severe haemolysis, since the maximum blood $\mathrm{Hb}$ loss in children without haemoglobinuria was $10 \mathrm{~g} / \mathrm{L}$. Erythrocyte-bound opsonins known to induce erythrophagocytosis, i.e., complement C $3 \mathrm{c}$ fragments and autologous IgG, were increased in all patients. In the patients with major haemolysis, the changes correlated to the haemolysis over time. Hence, a similar mechanism for predominantly extravascular erythrocyte clearance may be operative in acute malarial anaemia, normal erythrocyte senescence and other forms of acute haemolysis.
\end{abstract}

Keywords: malaria, Plasmodium falciparim, haemolytic anaemia, haemoglobinuria, children, Tanzania

\section{Introduction}

Childhood anaemia due to malaria represents a major medical problem in sub-Saharan Africa but its pathogenesis is complex (ABDALLA et al., 1980; NEWTON et al., 1997). A chronic type of anaemia which is frequently unrelated to current parasitaemia is common in semi-immune individuals living in holoendemic areas (PhILliPS \& PAsvol, 1992). Acute anaemia, superimposed on a low haemoglobin (Hb) level, is an important feature in young African children (EKVALI et al., 1998). Malaria triggers an imbalance in red blood cell (RBC) destruction and production which subsequently leads to anaemia, but there is still no comprehensive understanding of the relative contributions made by intravascular haemolysis, extravascular clearance of infected and uninfected RBC and bone-marrow dysfunction. Intravascular destruction of infected RBCs occurs at merogony (DEVAKUL et al., 1969), and extravascular phagocytosis of infected RBCs is caused by macrophages in the spleen, liver and bone-marrow (AIKAWA et al., 1980; SEED \& KREIER, 1980). Uninfected RBCs have a shortened life-span in malaria (PHILlips et al., 1986; LoOAREESUWAN et al., 1987) and, irrespective of how they are selected for removal, it has been generally acknowledged that their elimination occurs by erythrophagocytosis (CLARK \& ChaUdHRI, 1988). The acute haemolytic anaemia of malaria has been compared with premature RBC ageing (CONRAD, 1969), and a common model unifying the mechanism of RBC removal in normal senescence and in some pathological conditions with acute anaemia has been suggested (ARESE et al., 1991).

The objectives of the present study were to assess quantitatively the predominant mode (extravascular vs intravascular) of hacmolysis in acute cpisodes of childhood falciparum malaria, and to determine the relationship between parasitaemia and loss of blood $\mathrm{Hb}$. The deposition of complement factors and IgG was also studied, including their potential role in the extravascular removal of RBCs.

\section{Materials and Methods \\ Study subjects}

All children aged 6 months to 4 years presenting with a history of fever to the outpatient department of

\footnotetext{
* Author for correspondence; phone +46851771861 , fax
} +46851771806, e-mail hakekv@ki.se
Kisarawe district hospital, coastal Tanzania, between June and August 1997 were selected as possible study subjects. Out of 92 children with a confirmed axillary temperature $>38^{\circ} \mathrm{C}, 20$ satisfied the inclusion criteria of Plasmodium falciparum parasitaemia $\geqslant 1 \%$ and $\mathrm{Hb}$ $>50 \mathrm{~g} / \mathrm{L}$ without signs of cardiac failure. A physical examination including spleen size was made. No child had to be excluded owing to malnutrition. Oral informed consent was obtained from the mother for inhospital medical treatment and blood collection over 3 days.

\section{Clinical follow-up}

Approximately $0.75 \mathrm{~mL}$ venous blood was collected on admission and then once daily for 3 days under atraumatic conditions. Self-adhesive plastic bags (Coloplast ${ }^{\mathrm{B}}$ ) were attached to small children not in control of urine output for continuous urine collection; glass containers for micturition were used for older children. All specimens were microscopy checked to exclude urinary-tract infection and haematuria of other origin. Twenty-four hour portions of urine were frozen to $-20^{\circ} \mathrm{C}$ for later analysis of $\mathrm{Hb}$ content, as described below. Bodyweight, serum sodium and creatinine were determined on admission and on discharge to assess any changes in fluid balance. The children were given effective antimalarial therapy, either quinine alone or sulfadoxine-pyrimethamine and chloroquine. Blood transfusion was considered in any child who developed $\mathrm{Hb}<50 \mathrm{~g} / \mathrm{L}$ together with clinical signs of respiratory distress.

\section{Field laboratory methods}

Thick and thin blood films were treated with 5\% Giemsa stain and $P$. falciparum parasitaemia was estimated against 3000 RBCs. Blood $\mathrm{Hb}$ concentration was recorded in duplicate from venous blood, using the portable Haemocue" system and quality control kits (Haemocue AB, Sweden). After centrifugation, plasma or serum was atraumatically removed and frozen. $\mathrm{Hy}-$ potonic RBC membranes were prepared from each blood sample as described by DODGE et al. (1963). The membranes were prepared immediately after blood collection and frozen to $-20^{\circ} \mathrm{C}$ until analysis. Part of the RBC membrane collection was accidentally thawed owing to electrical power failure. The thawed samples were however discarded and 62 of the 70 specimens were analysed. 
Central laboratory methods

Plasma and urine $\mathrm{Hb}$ concentrations were analysed by spectrophotometry at the Department of Clinical Chemistry, Huddinge University Hospital, Sweden. Plasma haptoglobin and haemopexin, and serum sodium and creatinine, were analysed by routine methods at Sahlgrenska University Hospital, Sweden. Hb electrophoresis to identify $\mathrm{HbS}$ and screening for glucose 6-phosphate dehydrogenase (G6PD)-deficiency were also performed (BEUTLER, 1975).

RBC-bound IgG and complement fragment $\mathrm{C} 3 \mathrm{c}$ were measured on the hypotonic membranes prepared from the patients and from apparently healthy black children of comparable age without malaria taken as controls. In brief, membranes were labelled with goat anti-human $\mathrm{C} 3 \mathrm{c}$ or rabbit anti-human IgG and mouse second antibodies conjugated to alkaline phosphatase, as described (TURRINI et al., 1994). The alkaline phosphatase activity was measured by visible spectrophotometry at $405 \mathrm{~nm}$ using nitroblue tetrazolium/bromochlorophosphate as phosphatase substrate, and expressed as increments of $\mathrm{mOD} / 10 \mu \mathrm{L}$ membrane volume/min. For comparison, $100 \mathrm{mOD} / 10 \mu \mathrm{L}$ membrane volume/min corresponds to about $225 \mathrm{IgG}$ and $3800 \mathrm{C} 3 \mathrm{c}$ molecules bound per $\mathrm{RBC}$, respectively (TURRINI et al., 1991).

RBC-bound IgG molecules were eluted from the membranes and their specificity determined, as described by TURRINI et al. (1994). In brief, aggregation of band 3 can be elicited in normal RBCs by treatment with zinc/BS3 (bis-sulphosuccinimidyl-suberate). Eluted autologous IgG from the malaria patients was blotted on RBC membrane proteins prepared from zinc/BS3-treated RBC. After washing, anti-human IgG conjugated to alkaline phosphatase was used for visualizing eluted autologous IgG, and immunoblots were developed with nitroblue tetrazolium/bromochlorophosphate.

\section{Specific materials}

Sigma provided rabbit anti-human IgG antibodies, goat anti-human C3c antibodies, mouse anti-goat and anti-rabbit IgG antibodies conjugated to alkaline phosphatase (all affinity-purified polyclonals), detergents, bovine serum albumin and other chemicals. Electrophoresis material was from Biorad and protein A beads from Pharmacia Biotech; BS3 was from Pierce. Antibodies to band 3 cytoplasmic domain were a gift from P. S. Low (Purdue University, West Lafayette, IN, USA).

\section{Statistical methods}

The Wilcoxon rank-sum test was used for non-normal or sparse continuous data. Paired or 2-sample $t$ tests were used for continuous data with a normal distribution; parasitaemia and plasma $\mathrm{Hb}$ were normalized by logarithmic transformation.

\section{Ethical considerations}

Research approvals were obtained from the ethical committees of the Karolinska Institutet in Stockholm ( $\$ 98175$ ) and the Muhimbili College of Health Sciences in Dar es Salaam. Parents of study subjects provided oral informed consent.

\section{Results}

\section{Patient data}

Twenty children satisfied the study admission criteria of axillary temperature $>38^{\circ} \mathrm{C}, P$. falciparum parasitaemia $\geqslant 1 \%$ and admission blood $\mathrm{Hb}>50 \mathrm{~g} / \mathrm{L}$. The individual characteristics of the study subjects are shown in the Table. The mean age was 20 months (range 6-45) and there was no difference between males and females. One subject was G6PD-deficient (ID \#12) and one was identified as HbAS (ID \#11); the remaining children were $\mathrm{HbAA}$.
No child received blood transfusion during the study period and only ID \#5 required intravenous fluid replacement on a single occasion. Bodyweight, serum sodium and serum creatinine, all markers of fluid balance, were not significantly altered on discharge compared with admission values. Patient ID \#5 was transfused after the end of the study.

The geometric mean of individual maximum parasitaemias was $3.6 \%$ (range $1.7-20$ ). Individual parasitaemias peaked sometimes on admission $(n=11)$ and sometimes after $24 \mathrm{~h}(n-8)$. Only 2 of the 20 subjects were microscopy clear of parasites on the last blood collection.

\section{Blood haemoglobin concentrations}

The median change in blood $\mathrm{Hb}$ concentration over the 72 -h observation period was $-13 \mathrm{~g} / \mathrm{L}$ (range, -46 to +5 ). Assuming a blood volume of $0.075 \mathrm{~L} / \mathrm{kg}$ bodyweight (KING, 1998), the median amount of Hb lost from blood during the 72-h observation period was $11 \mathrm{~g}$ (maximum $37 \mathrm{~g}$ ). Major haemolytic episodes, defined as a decrease in blood Hb concentration $\geqslant 10 \mathrm{~g} / \mathrm{L}$ in $72 \mathrm{~h}$, were observed in 12 subjects; the remaining 8 children showed only temporary or minor changes in $\mathrm{Hb}$. In the 12 patients with major haemolysis, the drop in blood $\mathrm{Hb}$ was $>10 \%$ of the admission level. The loss of $\mathrm{Hb}$ was positively associated with age $(P=0.13)$. However, after adjusting for admission $\mathrm{Hb}$ concentration in a regression model, age was not significant in explaining blood $\mathrm{Hb}$ loss (Table). There was no association between spleen size or antimalarial treatment and blood $\mathrm{Hb}$ loss.

Percentage parasitaemia on admission was related to blood $\mathrm{Hb}$ loss during the $72 \mathrm{~h}$ observation period. The best fit for regression of parasitaemia on the reduction in $\mathrm{Hb}$ was however obtained by using the individual maximum parasitaemia $\left(R^{2}=0.58, P<0.0001\right.$ vs $R^{2}-0.39, P=0.004$ ) (Fig. 1). Overall, the median blood $\mathrm{Hb}$ loss (expressed as the percentage of admission $\mathrm{Hb}$ ) was $3 \cdot 7$ times (range, $0 \cdot 5-9$ ) larger than the corresponding reduction in infected cells. Individual differences in the relationship between parasitaemia and blood $\mathrm{Hb}$ loss were observed. For example, ID \#8 and \#15 with analogous $\mathrm{Hb}$ on admission and a reduction in parasitaemia of $4 \%$ under treatment showed individual blood $\mathrm{Hb}$ losses of $28 \mathrm{~g} / \mathrm{L}$ and $4 \mathrm{~g} / \mathrm{L}$, respectively (Table).

Plasma concentrations of $\mathrm{Hb}$, haptoglobin and haemopexin

Haemoglobinaemia occurred in 13 of the 20 children with detectable plasma $\mathrm{Hb}$ concentrations (Table). In these children the geometric mean plasma $\mathrm{Hb}$ concentration was $0.25 \mathrm{~g} / \mathrm{L}$ (range, $0-0.88$ ). At any point in time, the plasma $\mathrm{Hb}$ concentrations were $\ll 1 \%$ of

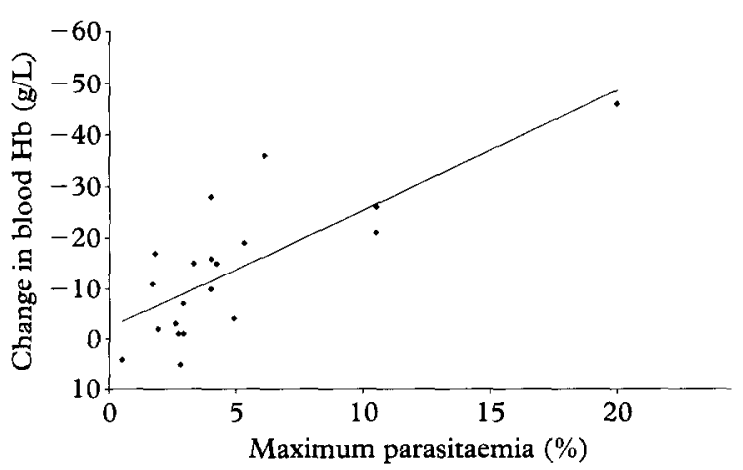

Fig. 1. The relationship between individual maximum parasitaemias and change in blood haemoglobin $(\mathrm{Hb})$ concentrations $(\mathrm{g} / \mathrm{L})$ over $72 \mathrm{~h}$ in 20 children with haemolysis due to acute $P$. falciparum malaria. Correlation coefficient, $r,=0.76$; $P<0.001$. 


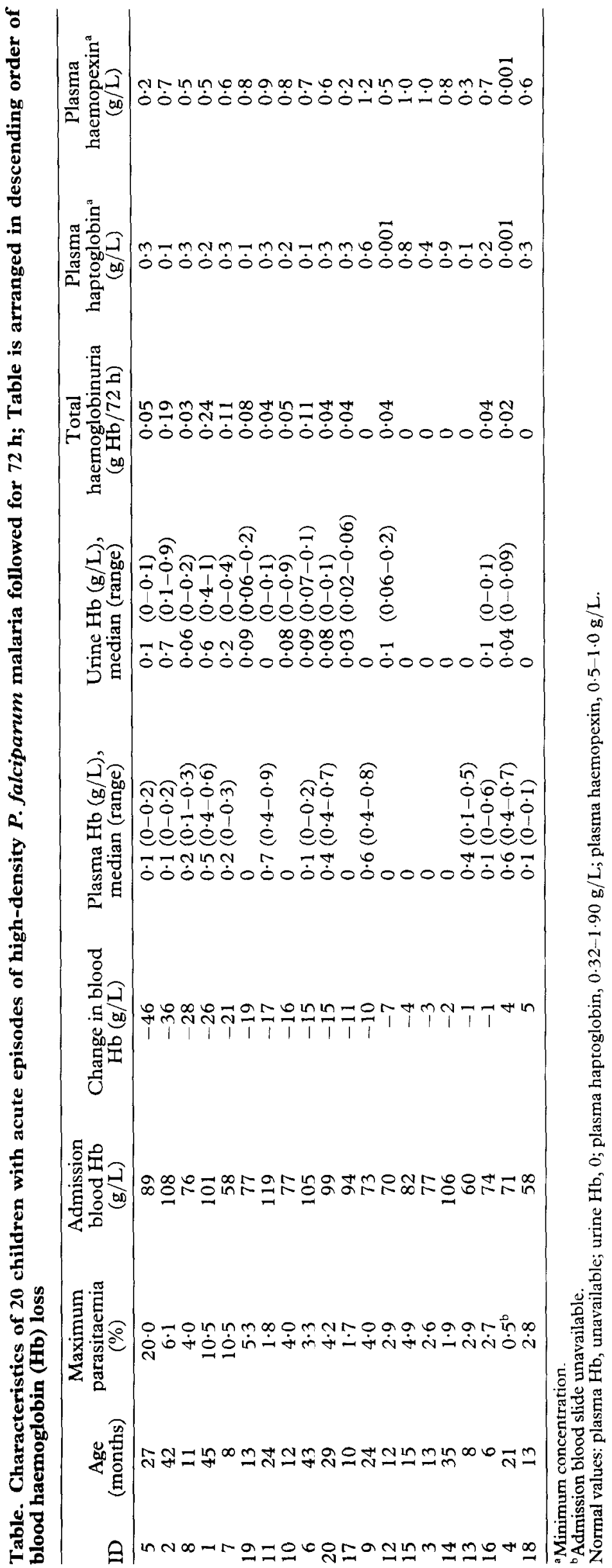


blood $\mathrm{Hb}$ concentrations obtained simultaneously. Haemoglobinaemia was not associated with blood $\mathrm{Hb}$ loss or with haemoglobinuria.

The median haptoglobin concentration was $0.3 \mathrm{~g} / \mathrm{L}$ (range, $0.001-1.8$ ) (Table). Haptoglobin concentrations were near or below the lower reference value in most subjects on all days. Five children (ID \#9, 11, 14, 15,20 ) with slightly higher haptoglobin concentrations on admission had a pronounced fall in haptoglobin concentration over the 72 -h observation period, but their haemopexin concentrations remained unchanged.

The median haemopexin concentration was $0.8 \mathrm{~g} / \mathrm{L}$ (range, $0 \cdot 1-1 \cdot 2$ ) (Table). Haemopexin concentrations were evenly distributed on admission, but there was an association between decline in plasma haemopexin over $72 \mathrm{~h}$ and drop in blood $\mathrm{Hb}$ concentration $(P=0.05)$.

\section{Haemoglobinuria}

Haemoglobinuria was detected in 14 of the 20 children (Table). The median urine $\mathrm{Hb}$ concentration was $0.06 \mathrm{~g} / \mathrm{L}$ (range, $0-0.97$ ) and only 2 specimens showed macroscopic haematuria. Multiplying the urine $\mathrm{Hb}$ concentration with urine output, the median loss of $\mathrm{Hb}$ in urine over $72 \mathrm{~h}$ in children with haemoglobinuria was $0.05 \mathrm{~g}$ (range, $0.03-0.24$ ). The occurrence of haemoglobinuria was associated with a greater fall in blood $\mathrm{Hb}$ concentration (Fig. 2). The median drop in blood $\mathrm{Hb}$ was $17 \mathrm{~g} / \mathrm{L}$ compared to $2.5 \mathrm{~g} / \mathrm{L}$ in those without haemoglobinuria $(P=0 \cdot 009)$. Individual differences in the relationship between haemoglobinuria and blood $\mathrm{Hb}$ loss were observed, e.g., in ID \#2 and \#5 with similar blood $\mathrm{Hb}$ losses, a 4-fold difference in haemoglobinuria was detected (Table). Haemoglobinuria was associated with indices of intravascular haemolysis, i.e., the individual minimum level of plasma haptoglobin $(P=0.004)$ and the reduction in plasma haemopexin over $72 \mathrm{~h}(P=0.04)$. Haemoglobinuria was, however, not related to percentage parasitaemia $(P=0.34)$. In children with haemoglobinuria, the median daily urine output decreased linearly with increasing $\mathrm{Hb}$ excretion and was lower than in subjects without $\mathrm{Hb}$ in urine $(P=0.03)$. No child developed anuria. There was no association between haemoglobinuria and quinine treatment $(P=0.91)$. As an example of a severe haemolytic episode, Figure 3 illustrates the individual concentrations of blood $\mathrm{Hb}$, plasma $\mathrm{Hb}$ and urine $\mathrm{Hb}$ obtained in ID \#5.

\section{RBC-bound complement $C 3 c$ and IgG}

The median level of RBC-bound complement fragment $\mathrm{C} 3 \mathrm{c}$ was $202 \mathrm{mOD} / 10 \mu \mathrm{L}$ membrane volume/ min (range, 152-325), and the median level of autologous IgG was $40 \mathrm{mOD} / 10 \mu \mathrm{L}$ membrane volume/min (range, 31-56). Both levels were significantly higher

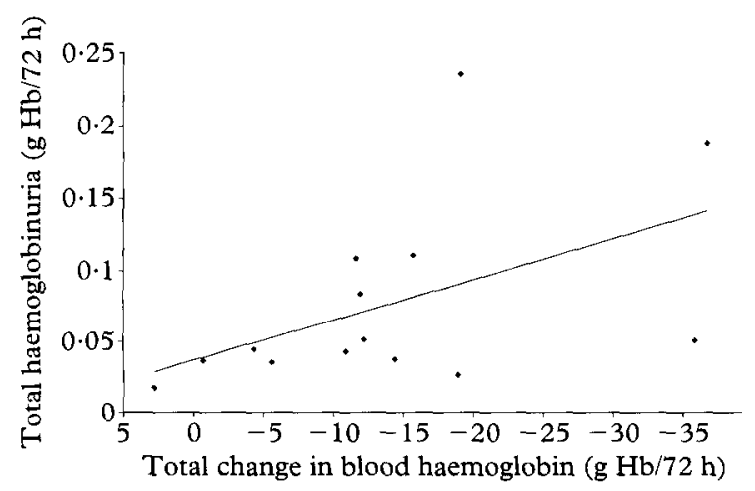

Fig. 2. The relationship between change in blood haemoglobin $(\mathrm{Hb} ; \mathrm{g})$ and total haemoglobinuria $(\mathrm{g})$ over $72 \mathrm{~h}$ in children with haemolysis due to acute $P$. falciparum malaria. Correlation coefficient, $r,=0.50 ; P=0.07$. For calculation of blood $\mathrm{Hb}(\mathrm{g})$ from blood $\mathrm{Hb}$ concentration $(\mathrm{g} / \mathrm{L})$, a blood volume of $0.075 \mathrm{~L} / \mathrm{kg}$ bodyweight was assumed (KING, 1998).

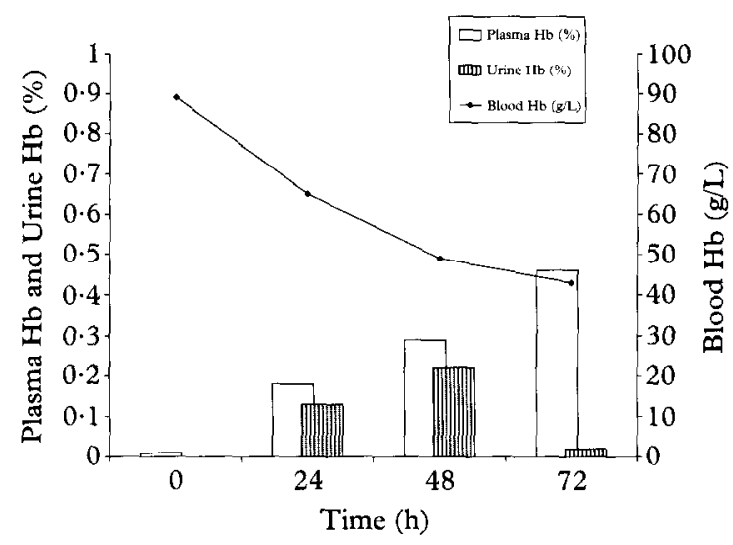

Fig. 3. Behaviour of total blood haemoglobin $(\mathrm{Hb})$, plasma $\mathrm{Hb}$ and urine $\mathrm{Hb}$ over $72 \mathrm{~h}$ during a severe haemolytic episode due to acute $P$. falciparum malaria (ID \#5). Total blood $\mathrm{Hb}$ concentrations $(g / L)$ (line, right $y$-axis); concentrations $(g / L)$ of plasma $\mathrm{Hb}$ (open columns, left $y$-axis) and urine $\mathrm{Hb}$ (stippled columns, left $y$-axis) are expressed as percent of blood $\mathrm{Hb}$ concentrations.

than those obtained from healthy controls $(P<0.05)$ (Fig. 4). The change over time of both markers in 12 patients with major haemolysis is shown in Figure 4. On admission, the median $\mathrm{C} 3 \mathrm{c}$ level was $210 \mathrm{mOD}$, i.e., 7 -fold higher than controls. After $24 \mathrm{~h}$, further
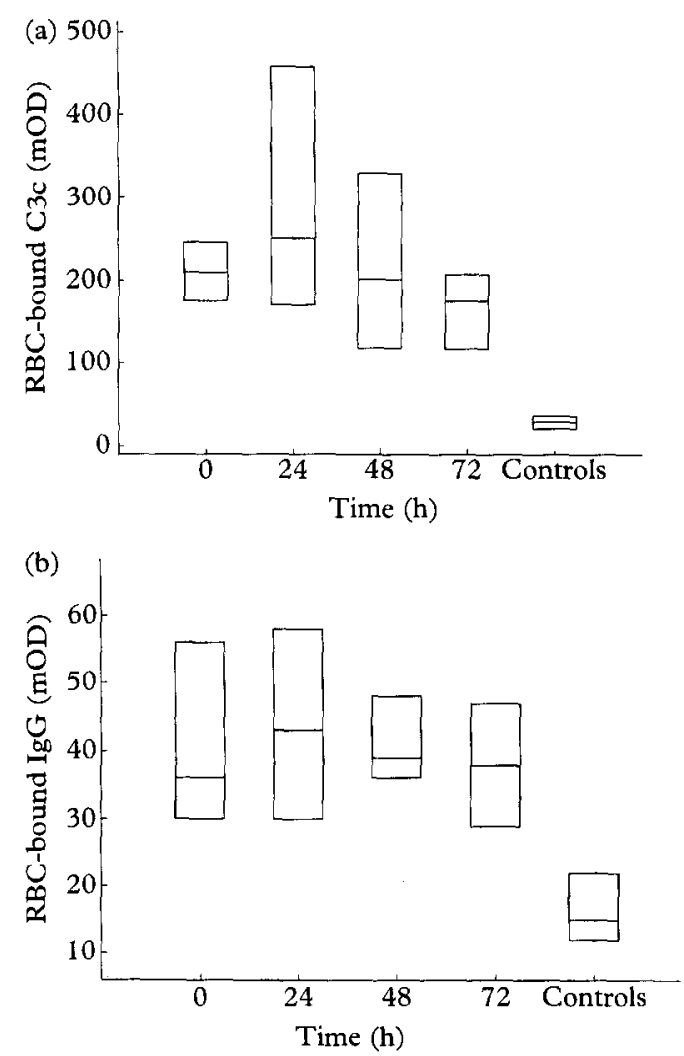

Fig. 4. Red blood cell (RBC)-bound complement fragment $\mathrm{C} 3 \mathrm{c}$ (Fig. 4a) and IgG (Fig. 4b) in patients with major haemolysis due to acute $P$. falciparum malaria at $0,24,48$ and 72 hours after the onset of treatment. Box plots with medians, lower and upper quartile values of 12 patients with severe haemolysis [haemoglobin ( $\mathrm{Hb}) \operatorname{loss}>10 \mathrm{~g} / \mathrm{L}$ ] are shown. Average $\mathrm{Hb}$ loss was $8 \mathrm{~g} / \mathrm{L}$ in the first $24-\mathrm{h}$ period, $7 \mathrm{~g} / \mathrm{L}$ in the second $24-\mathrm{h}$ period and $6 \mathrm{~g} / \mathrm{L}$ in the third $24-\mathrm{h}$ period. The values of alkaline phosphatase activity of second antibodies to anti-human $\mathrm{C} 3 \mathrm{C}$ and anti-human Ig $\mathrm{G}$ are expressed as $\mathrm{mOD}_{405} / 10 \mu \mathrm{L}$ membrane volume/min. All differences to control values are statistically significant $(P<0.05)$. 
increases in bound $\mathrm{C} 3 \mathrm{c}$ occurred with median levels 8.5-fold higher than controls. The increase in IgG was statistically significant over controls at all times but was less evident than the increase in C3c. Both levels declined over $72 \mathrm{~h}$. The autologous IgG eluted from 4 malaria patients with major haemolysis was blotted on to membrane proteins containing aggregated band 3 isolated from zinc/BS3-treated RBCs. In 6 unthawed samples [ID \#1 (3 samples), 5, 9 and 19] the eluted antibodies reacted with the aggregated band 3 (not shown).

\section{Discussion}

Parasitaemia and blood $\mathrm{Hb}$ loss

Twenty episodes of high-level $P$. falciparum parasitaemia in children from an holoendemic area were prospectively investigated and quantitatively assessed for haemolysis. Only untransfused children with $\mathrm{Hb}>50 \mathrm{~g} / \mathrm{L}$ were studied. A wide range of blood $\mathrm{Hb}$ losses occurred during the observation period (Table). In all major haemolytic episodes the rapid blood $\mathrm{Hb}$ loss levelled out over $72 \mathrm{~h}$ as if self-limited, or, more likely, dependent on vanishing parasite load due to antimalarial therapy. The recorded $\mathrm{Hb}$ losses were not due to haemodilution by intravenous fluid replacement, and the indices of fluid balance were not significantly altered during the observation period. There was no relationship between the reduction in $\mathrm{Hb}$ and spleen size on admission. However, during antimalarial treatment the return to the circulation of RBCs pooled in the spleen could lead to an increase in $\mathrm{Hb}$ (WHITE, 1998), possibly explaining the increase in $\mathrm{Hb}$ observed in subjects with ongoing haemolysis (see for example ID \#4 and \#18; Table).

There was an overall linear relationship between maximum parasitaemia and the fall in blood $\mathrm{Hb}$ concentration (Fig. 1). However, the decrease in blood $\mathrm{Hb}$ was up to 9 times larger than the reduction in parasitaemia, possibly indicating the removal of variable numbers of uninfected cells (WHITE, 1998; JAKEMAN et al., 1999). At parasite iso-density, some subjects (e.g., ID \#8) experienced a pronounced drop in blood $\mathrm{Hb}$ whereas others (e.g., ID \#15) were less affected (Table). The discrepancy between parasitaemia and drop in $\mathrm{Hb}$ may be due to selective removal of parasites from infected RBCs by macrophages ('pitting') (KU MARATILAKE et al., 1994). Differences in immune status and phagocytic function, and variable sequestration in the deep circulation, may also have contributed (Ho \& WHITE, 1999).

Reticulocyte counts reflecting erythropoietic activity were not available. However, it was unlikely that a strong reticulocyte response would have modified the haematological status within the 72-h observation period, as reticulocytosis has been shown to develop only after parasite clearance (ABDALLA et al., 1980; KURTZHALS et al., 1997; NEWTON et al., 1997), and only 2 children were cleared from parasites on the last blood collection.

\section{Mode of haemolysis}

The relative shares of intravascular and extravascular haemolysis were semi-quantitatively determined by balancing the disappearance of $\mathrm{Hb}$ from blood with the increase of $\mathrm{IIb}$ in the plasma and the recovery of $\mathrm{Hb}$ in the urine. In intravascular haemolysis, $\mathrm{Hb}$ released into plasma binds to haptoglobin and haemopexin. When the plasma binding capacity is exceeded haemoglobinuria develops (PIMSTONE, 1972). In extravascular haemolysis, $\mathrm{Hb}$ is degraded to bilirubin within the reticulocndothelial system. Hence, in predominantly intravascular haemolysis, loss of blood $\mathrm{Hb}$ is expected to be recovered as $\mathrm{Hb}$ in the plasma and urine, whereas extravascular haemolysis may be indirectly determined as the difference between total blood $\mathrm{Hb}$ loss and the signs of intravascular haemolysis.
In the present study, the increases in plasma $\mathrm{Hb}$ were minor and $\ll 1 \%$ of blood $\mathrm{Hb}$ concentrations, suggesting a low degree of intravascular haemolysis. Similar plasma $\mathrm{Hb}$ levels have been recorded in aduits with $P$. falciparum malaria (DEVAKUL et al., 1969). The total amount of $\mathrm{Hb}$ liberated into plasma over time is not easily determined, however, since the plasma $\mathrm{Hb}$ concentration is influenced by several factors, e.g., the rate of inflow of haemoglobin into plasma, organ uptake and metabolism of $\mathrm{Hb}$ and its carrier proteins, and the rate of renal reabsorption and excretion of $\mathrm{Hb}$.

The plasma $\mathrm{Hb}$ did not show a linear relationship with haemoglobinuria or blood Hb loss. There may be several reasons for this. Plasma $\mathrm{Hb}$ analysis is very sensitive to in-vitro haemolysis by specimen collection and handling. Although measures were taken to prevent this, results of plasma $\mathrm{Hb}$ may have overestimated the degree of intravascular haemolysis. In addition, the spectrophotometric $\mathrm{Hb}$ reading may have been affected by individual differences in plasma turbidity caused by fibronectin precipitation in heparinized plasma. Furthermore, daily plasma $\mathrm{Hb}$ determinations were not able to capture brief episodes of intravascular haemolysis, and haemoglobinuria occurred despite the absence of recorded haemoglobinaemia (see for example ID \#12; Table).

Haemoglobinuria was insignificant and only a minor portion of $\mathrm{Hb}$ lost from blood was recovered in the urine. Even in children with major haemolysis haemoglobinuria constituted $<1 \%$ of blood $\mathrm{Hb}$ loss. Haemoglobinuria does not occur until the plasma binding capacity for $\mathrm{Hb}$ has been saturated and free $\mathrm{Hb}$ is filtered through the glomeruli (LowENSTEIN et al., 1961). The capacity to reabsorb $\mathrm{Hb}$ in the renal tubuli is minor (LATHEM, 1959), and the vast majority of $\mathrm{Hb}$ filtered through the kidneys is therefore recovered in the urine. It has been suggested that $0.3-0.6 \mathrm{~g} / \mathrm{L}$ free $\mathrm{Hb}$ is the renal threshold for haemoglobinuria (LATHEM, 1959; WEATHERALL, 1996).

In our study, the geometric mean plasma $\mathrm{Hb}$ concentration in the children was $0.25 \mathrm{~g} / \mathrm{L}$, but this included both free and protein-bound $\mathrm{Hb}$. It is thus plausible that plasma binding was a quantitatively important rescue mechanism for $\mathrm{I} \mathrm{Ib}$ in the children. The potential of haptoglobin and haemopexin to act as scavenger for $\mathrm{Hb}$ is, however, small, particularly in children. The release of $1 \mathrm{~g} \mathrm{Hb}$ into plasma fully saturates the plasma binding proteins in adults (GIBLETT, 1968). In children, only a small fraction of this amount may be bound, since the plasma volumes are considerably smaller and the haptoglobin concentrations substantially lower.

The haptoglobin levels were commonly depressed already on admission. Similar levels have been reported in severe childhood anaemia (NEWTON et al., 1997). Low levels may indicate ongoing intravascular haemolysis by asymptomatic malaria infection, but haptoglobin concentrations are age dependent and therefore low in young children (GIBLETT, 1968). In a few subjects with slightly higher admission haptoglobin, the levels decreased rapidly. Reduction in plasma haemopexin, a more specific but less sensitive marker for intravascular haemolysis, was more pronounced in episodes with severe haemolysis. This is consistent with haemopexin acting as second carrier protein for $\mathrm{Hb}$ in the plasma (MULLER-EBERHARD, 1970). Reductions in both haptoglobin and haemopexin were associated with haemoglobinuria and thus reflected intravascular haemolysis.

In conclusion, our data indicate that extravascular RBC removal, most likely by erythrophagocytosis, was the predominant mode of haemolysis, since disappearance of blood $\mathrm{Hb}$ corresponded to only small increases in plasma $\mathrm{Hb}$, minor haemoglobinuria and limited haemoglobin binding capacity of the plasma in the children. The absence of multi-organ failure in the patients supported the predominance of extravascular 
haemolysis, since such a complication would be likely if vast amounts of RBC lysed intravascularly. A linear association was found between blood $\mathrm{Hb}$ loss and haemoglobinuria (Fig. 2), indicating that intravascular haemolysis increased in parallel to blood Hb loss. No clinical threshold value for haemoglobinuria could, however, be identified from blood $\mathrm{Hb}$ loss. In addition, no relationship was found between parasitaemia and haemoglobinuria, despite the observed relationships between parasitaemia-blood $\mathrm{Hb}$ loss and blood $\mathrm{Hb}$ loss haemoglobinuria.

Parasite densities were expressed as percentage infected RBCs, a more convenient unit in high parasitaemias than parasite counts per $\mu \mathrm{L}$ blood. The total parasite biomass will then depend on the total number of RBCs. Since practically all children were anaemic, we consider percent infected RBCs to be an acceptable relative estimate of biomass. To report absolute parasite counts involves counting parasites against white blood cells (WHO, 1991), but as white cell counts are age dependent (TRAPE et al., 1994), a common standard count may not have been appropriate for all cohort children.

\section{Mechanism of extravascular $R B C$ clearance}

Increased levels of the RBC-bound opsonins known to induce erythrophagocytosis, C3c complement fragment and IgG with specificity for aggregated band 3, were consistently observed in the patients. In children with major haemolysis, there was an initial increase in bound $C 3 c$ and IgG that gradually declined with the elimination of parasites. Particularly the early increase in bound complement was prominent. Recognition of deposited complement by complement receptor type 1 (CR1) of the macrophage is a very efficient way to induce removal of effete or damaged RBCs by phagocytosis (see LUTZ, 1990 for review). Previous studies in vitro have shown complement activation by the surface of $P$. falciparum-infected RBCs (STANLEY et al., 1984), and indicated that increased phagocytosis of ring-form infected human RBCs opsonized by non-immune serum was mostly dependent on complement fragment deposition and was mediated by CR1 on the macrophage (TURRINI et al., 1992). In vivo, antibody deposition on infected and uninfected RBCs as well as antibody-mediated phagocytosis has been observed by numerous authors (FACER et al., 1979; VERNES, 1980; FACER \& BROWN, 1981; JEJE et al., 1983; ABDALLA, 1988). Oxidative aggregation of band 3 and subsequent deposition of naturally occurring anti-band $3 \mathrm{IgG}$ has been suggested to induce limited complement activation and $\mathrm{C} 3 \mathrm{~b}-\mathrm{C} 3 \mathrm{c}$ deposition on the $\mathrm{RBC}$ membrane (LUTZ, 1990). Recent data indicate that band 3 is aggregated in $P$. falciparum-infected RBCs (GIRIBALDI et al., 2001). In the present study, eluted autologous IgG recognized aggregated band 3 present in $\mathrm{RBC}$ membranes prepared from zinc/BS3-treated RBCs (TURRINI et al., 1994). This may suggest that the mechanism of haemolysis seen in the elimination of normal senescent or artificially modified RBCs (BEPPU et al., 1990; LUTZ, 1990) may also operate in presumably non-immune children with malaria. The suggested mechanism is in agreement with previous data reported by FACER et al. (1979) showing that, in Gambian children with malaria, sensitization of RBCs with complement fragments was associated with anaemia.

\section{Clinical implications}

All major blood Hb drop occurred with limited signs of intravascular haemolysis, i.e., minor haemoglobinuria and increase in plasma $\mathrm{Hb}$. Children without haemoglobinuria had a maximum blood $\mathrm{Hb}$ loss of $10 \mathrm{~g} / \mathrm{L}$ (Table). A major $\mathrm{Hb}$ drop over a short time period could be deleterious for oxygen supply to vital organs, whereas a continuously low $\mathrm{Hb}$ concentration has less clinical implications owing to gradual physical adjust- ment (CARSON et al., 1988). Blood transfusions are life saving in anaemic children with clinical signs of respiratory distress, but should be used restrictively in areas without optimal blood-donor screening, given the risk for HIV transmission (LACKRITZ et al., 1997). Under these circumstances, a urine dipstick test for $\mathrm{Hb}$ could help in the decision process to refrain from blood transfusion in a child admitted with clinical malaria and hyperparasitaemia. In the absence of haemoglobinuria, the risk for a significant drop in blood $\mathrm{Hb}$ concentration within $72 \mathrm{~h}$ was limited. Validation of this procedure, however, needs a larger sample size than that of the present study.

\section{Acknowledgements}

Kerstin Aronsson, paediatric nurse, was responsible for patient care and venous blood collections; $\mathrm{Dr} \mathrm{H}$. V. C. Mloka for local support; Dr Sofia Andersson for microscopy examinations; and Michel Willcox for $\mathrm{Hb}$ electrophoreses. This study was supported by the Swedish International Development Agency (SWE-95-188) and Compagnia di San Paolo, Torino, Italy (grant to P.A.). Additional support was received from Pharmacia-Upjohn Company and Emil Andersson Foundation.

\section{References}

Abdalla, S. H. (1988). Peripheral blood and bone marrow leucocytes in Gambian children with malaria: numerical changes and evaluation of phagocytosis. Annals of Tropical Paediatrics, 8, 250-258.

Abdalla, S., Weatherall, D. J., Wickramasinghe, S. N. \& Hughes, $M$. (1980). The anaemia of $P$. falciparum malaria. British foumal of Haematology, 46, 171-183.

Aikawa, M., Suzuki, M. \& Gutierrez, Y. (1980). Pathology of malaria. In Malaria, Kreier, J. P. (editor). New York: Academic Press, pp. 47-102.

Arese, P., Turrini, F., Bussolino, F., Lutz, H. U., Chiu, D., Zuo, L., Kuypers, F. \& Ginsburg, H. (1991). Recognition signals for phagocytic removal of favic, malaria-infected and sickled erythrocytes. Advances in Experimental Medicine and Biology, 307, 317-327.

Beppu, M., Mizukami, A., Nagoya, M. \& Kikugawa, K. (1990). Binding of anti-band 3 autoantibody to oxidatively damaged erythrocytes. Formation of senescent antigen on erythrocyte surface by an oxidative mechanism. Fournal of Biological Chemistry, 265, 3226-3233.

Bcutler, E. (1975). Red Cell Metabolism. A Manual of Biochemical Methods. New York: Grune \& Stratton, pp. 62-64.

Carson, J. L., Poses, R. M., Spence, R. K. \& Bonavita, G. (1988). Severity of anaemia and operative mortality and morbidity. Lancet, i, 727-729.

Clark, I. A. \& Chaudhri, G. (1988). Tumour necrosis factor may contribute to the anaemia of malaria by causing dyserythropoiesis and erythrophagocytosis. British fournal of Haematology, 70, 99-103.

Conrad, M. E. (1969). Pathophysiology of malaria. Hematologic observations in human and animal studies. Annals of Internal Medicine, 70, 134-141.

Devakul, K., Harinasuta, T. \& Kanakakorn, K. (1969). Erythrocyte destruction in Plasmodium falciparum malaria: an investigation of intravascular haemolysis. Annals of Tropical Medicine and Parasitology, 63, 317-325.

Dodge, J. T., Mitchell, C. \& Hanahan, D. J. (1963). The preparation and chemical characteristics of hemoglobin-free ghosts of human erythrocytes. Archives of Biochemistry and Biophysics, 100, 119-129.

Ekvall, H., Premji, Z. \& Biorkman, A. (1998). Chlornquine treatment for uncomplicated childhood malaria in an area with drug resistance: early treatment failure aggravates anaemia. Transactions of the Royal Society of Tropical Medicine and Hygiene, 92, 556-560.

Facer, C. A. \& Brown, J. (1981). Monocyte erythrophagocytosis in falciparum malaria. Lancet, $\mathbf{i}, 897-898$.

Facer, C. A., Bray, R. S. \& Brown, J. (1979). Direct Coombs antiglobulin reactions in Gambian children with Plasmodium falciparum malaria. I. Incidence and class specificity. Clinical and Experimental Immunology, 35, 119-127.

Giblett, E. (1968). The haptoglobin system. Series Haematologica, $1,3-20$.

Giribaldi, G., Ulliers, D., Mannu, F., Arese, P. \& Turrini, F. (2001). Growth of Plasmodium falciparum induces stagedependent haemichrome formation, oxidative aggregation of band 3, membrane deposition of complement and anti- 
bodies, and phagocytosis of parasitized erythrocytes. British foumal of Haematology, 113, 492-499.

Ho, M. \& White, N. J. (1999). Molecular mechanisms of cytoadherence in malaria. American foumal of Physiology, 276, C1231-C1242.

Jakeman, G. N., Saul, A., Hogarth, W. L. \& Collins, W. E. (1999). Anaemia of acute malaria infections in non-immune patients primarily results from destruction of uninfected erythrocytes. Parasitology, 119, 127-133.

Jeje, O. M., Kelton, J. G. \& Blajchman, M. A. (1983). Quantitation of red cell membrane associated immunoglobulin in children with Plasmodium falciparum parasitaemia. British fournal of Haematology, 54, 567-572.

King, D. J. (1998). Disorders of the blood and reticuloendothelial system. In: Forfar and Ameil's Textbook of Pediatrics, Campbell, A. G. M. \& McIntosh, N. (editors). New York: Churchill Livingstone, p. 851.

Kumaratilake, L. M., Ferrante, A., Kamaratilake, J. S. \& Allison, A. C. (1994). Extraction of intraerythrocytic malarial parasites by phagocytic cells. Parasitology Today, 10, 193-196.

Kurtzhals, J. A., Rodrigues, O., Addae, M., Commey, J. O., Nkrumah, F. K. \& Hviid, L. (1997). Reversible suppression of bone marrow response to erythropoietin in Plasmodium falciparum malaria. British fournal of Haematology, 97, $169-174$.

Lackritz, E. M., Hightower, A. W., Zucker, J. R., Ruebush, T. K. II, Onudi, C. O., Steketee, R. W., Were, J. B., Patrick, E. \& Campbell, C. C. (1997). Longitudinal evaluation of severely anemic children in Kenya: the effect of transfusion on mortality and hematologic recovery. AIDS, 11, $1487-$ 1494.

Lathem, W. (1959). The renal excretion of hemoglobin regulatory mechanisms and the differential excretion of free and protein-bound hemoglobin. Fournal of Clinical Investigation, 38, 652-658.

Looareesuwan, S., Merry, A. H., Phillips, R. E., Pleehachinda, R., Wattanagoon, Y., Ho, M., Charoenlarp, P., Warrell, D. A. \& Weatherall, D. J. (1987). Reduced erythrocyte survival following clearance of malarial parasitaemia in Thai patients. British foumal of Haematology, 67, 473-478.

Lowenstein, J., Faulstick, D., Yiengst, M. \& Shock, N (1961). The glomerular clearance and renal transport of hemoglobin in adult males. Fournal of Clinical Investigation, 40, $1172-1177$

Lutz, H. U. (1990). Erythrocytc clearance. In: Blood Cells. Subcellular Biochemistry, Vol. 17, Erythroid Cells, Harris, J. R. (editor). New York: Plenum Press, pp. 81-120.

Muller-Eberhard, U. (1970). Hemopexin. New England fournal of Medicine, 283, 1090-1094.

Newton, C. R., Warn, P. A., Winstanley, P. A., Peshu, N., Snow, R. W., Pasvol, G. \& Marsh, K. (1997). Severe anaemia in children living in a malaria endemic area of Kenya. Tropical Medicine and International Health, 2, $165-178$
Phillips, R. E. \& Pasvol, G. (1992). Anaemia of Plasmodium falciparum malaria. Baillières Clinical Haematology, 5, 315-330.

Phillips, R. E., Looareesuwan, S., Warrell, D. A., Lee, S. H., Karbwang, J., Warrell, M. J., White, N. J., Swasdichai, C. \& Weatherall, D. J. (1986). The importance of anaemia in cerebral and uncomplicated falciparum malaria: role of complications, dyserythropoiesis and iron sequestration. Quarterly Fournal of Medicine, 58, 305-323.

Pimstone, N. R. (1972). Renal degradation of hemoglobin. Seminars in Hematology, 9, 31-42.

Seed, T. M \& Kreier, J. P. (1980). Erythrocyte destruction mechanisms in malaria. In: Malaria, Vol. 2., Kreier, J. P. (editor), New York: Academic Press, pp. 1-46.

Stanley, H. A., Mayes, J. T., Cooper, N. R. \& Reese, R. T. (1984). Complement activation by the surface of Plasmodium falciparum infected erythrocytes. Molecular Immunology, 21, 145- 150 .

Trape, J. F., Rogier, C., Konate, L., Diagne, N., Bouganali, H., Canque, B., Legros, F., Badji, A., Ndiaye, G., Ndiaye, P. et al. (1994). The Dielmo project: a longitudinal study of natural malaria infection and the mechanisms of protective immunity in a community living in a holoendemic area of Senegal. American fournal of Tropical Medicine and Hygiene, 51, 123-137.

Turrini, F., Arese, P., Yuan, J. \& Low, P. S. (1991). Clustering of integral membrane proteins of the human erythrocyte membrane stimulates autologous IgG binding, complement deposition, and phagocytosis. Foumal of Biological Chemistry, 266, 23611-23617.

Turrini, F., Ginsburg, H., Bussolino, F., Pescarmona, G. P., Serra, M. V. \& Arese, P. (1992). Phagocytosis of Plasmodium falciparum-infected human red blood cells by human monocytes: involvement of immune and nonimmune determinants and dependence on parasite developmental stage. Blood, 80, 801-808.

Turrini, F., Mannu, F., Cappadoro, M., Ulliers, D., Giribaldi, G. \& Arese, P. (1994). Binding of naturally occurring antibodies to oxidatively and nonoxidatively modified erythrocyte band 3. Biochimica et Biophysica Acta, 1190, 297-303.

Vernes, A. (1980). Phagocytosis of $P$. falciparum erythrocytes by peripheral monocytes. Lancet, ii, $1297-1298$.

Weatherall, D. J. (1996). The red cell. In: Oxford Textbook of Medicine, Vol. 3, Weatherall, D. J., Ledingham, J. G. G. \& Warrell, D. A. (editors). Oxford: Oxford University Press, p. 3526 .

White, N. J. (1998). Malaria pathophysiology. In: Malaria: Parasite Biology, Pathogenesis and Protection, Sherman, I. W. (editor). Washington D.C.: ASM press, pp. 371-385.

WHO (1991). Basic Malaria Microscopy. Part I. Learner's Guide. Geneva, Switzerland: World Health Organization.

Received 28 fuly 2000; revised 21 May 2001; accepted for publication 23 May 2001

\section{Announcement}

\section{ROYAL SOCIETY OF TROPICAL MEDICINE AND HYGIENE Robert Cochrane Fund for Leprosy}

The fund, in memory of the great leprologist Robert Cochrane, is administered by the Royal Society of Tropical Medicine and Hygiene. It is used to finance up to three travel fellowships each year to a maximum value of $£ 1000$ each.

The fund will support travel for

- Leprosy workers who need to obtain practical training in field work or in research

- Experienced leprologists to provide practical clinical training in a developing country

There is no restriction on the country of origin or destination providing the above requirements are met.

Applications must be made at least six months ahead of the proposed trip, sponsored by a suitable representative of the applicant's employer or study centre and agreed by the host organization. A short report on the travel/study should be submitted, within one month of the recipient's return. Application forms are available from the Administrator, Royal Society of Tropical Medicine and Hygiene, Manson House, 26 Portland Place, London, W1B 1EY, UK; fax +44 (0)20 74361389, e-mail mail@rstmh.org 